\title{
Choice, Cyber Charter Schools, and the Educational Marketplace for Rural
}

\section{School Districts}

\author{
Bryan Mann \\ Pennsylvania State University \\ Stephen Kotok \\ University of Texas at El Paso \\ Erica Frankenberg
}

Ed Fuller

Kai Schafft

Pennsylvania State University

\begin{abstract}
Pennsylvania is a state with significant proportions of students who attend rural schools, as well as students who attend charter schools. This study examines enrollment patterns of students in brick and mortar and cyber charter schools in Pennsylvania and how these enrollment patterns differ across geographic locale. We analyze studentlevel enrollment data, controlling for demographic characteristics, and find that, in contrast to brick and mortar schools, cyber charter schools attract students from a variety of locales across the urban-rural continuum. However, rural students exhibit the greatest likelihood of attending cyber charter schools. We discuss the implications of these findings in relation to educational equity, cyber charter school underperformance, and the fiscal impacts of charter schools on the budgets of small school districts.
\end{abstract}

\section{Keywords: charter schools, cyber charter schools, rural education, student mobility}

Federal and state-level policies have promoted the growth of charter schools in the United States for more than two decades (Berends, 2015). Since 1992 when the first charter school opened in Minnesota, charter schools have become an increasingly prominent part of the educational and public policy landscape. Technically considered public schools, charter schools receive tax dollars to cover their operational costs. Instead of answering to locally elected school boards, however, charter schools are structured by and accountable to individual charters that define each school's mission and educational purpose. The formulation and authorization of these charters differ depending on state statute, allowing different variations of either non-profit or private entities to run the schools. By design, charter schools are exempt from many of the regulations and procedures that traditional public schools must follow, including but not limited to regulations like the length of the school day and hiring and firing procedures. Charter schools have, thus, been identified as representing important new opportunities for educational innovation (U.S. Department of Education, 2004). Embodying neoliberal commitments and using market-based solutions to educational problems (Gallo, 2014; Howley, 2014; Peters, 2012), advocates argue that charter schools increase competition within public education and, consequently, promote both greater fiscal efficiencies and improved educational outcomes in all schools, including those in rural locations (Gronberg, Jansen, \& Taylor, 2012; Henig, 2012; Smarick, 2014).

At the national level, charter schooling figured prominently within recent legislation and executive actions such as the Elementary and Secondary Education (ESEA) waivers as a means of increasing educational achievement and closing achievement gaps (Bankston et al., 2013; U.S. Department of Education, 2004). The recent Race to the Top program provided strong incentives for states to adopt policies that would increase the number of charter schools. More than 40 states have authorized the creation of charter schools, and charter schools have been promoted by the last five Presidential administrations (Siegel-Hawley \& Frankenberg, 2011). Particularly in urban areas with large numbers 
of "failing" schools, charter school enrollment has shown disproportionate growth (Henig, 2012).

The political conversations and research findings about charter schools tend to focus on urban school districts, most likely due to the increases in brick and mortar charter school enrollment by urban students. However, less attention has been paid to how the proliferation of charter school enrollments affects rural schools. The purpose of this study, therefore, is to consider charter school enrollment in rural contexts and, in particular, how cyber charter schools may affect rural school district enrollments and operations.

This study specifically focuses on Pennsylvania for two principal reasons. First, the state legislature has enthusiastically supported the proliferation of both brick and mortar and cyber charter schools (DeJarnatt, 2013; Gallo, 2014). The legislature enacted a charter school law in 1997 and the first cyber charters subsequently opened in 1998 (with the Pennsylvania Department of Education becoming the official authorizer of cyber charter schools in 2002). By the 2011-12 academic year, there were more than 100,000 students enrolled in charter schools across the Commonwealth, accounting for about $6 \%$ of Pennsylvania's total student enrollment and representing one of the largest charter school enrollments across the country. Pennsylvania has paid out more than $\$ 4.7$ billion in subsidies to charter schools between academic year 2006-07 and 2011-12 at a time of unprecedented state education budget cuts, including $\$ 1$ billion in K-12 education budget cuts in 2011 (Schafft et al., 2014). Second, despite the large metropolitan areas of Philadelphia and Pittsburgh, Pennsylvania also has the third largest rural population in the nation, at 2.7 million residents, ${ }^{1}$ and the $9^{\text {th }}$ largest rural school enrollment (Johnson, Showalter, Klein, \& Lester, 2014). This makes Pennsylvania a critical case with regard to questions about both charter school enrollment and how charter school enrollment differs by charter school type and geographic location of the traditional public schools that students leave for charter schools.

\section{Charter Schools, Student Outcomes, and Educational Access: A Mixed Record}

Despite a public policy environment that has been largely favorable towards charter schools, researchers have found mixed results regarding the impact charter schools have on student outcomes

\footnotetext{
${ }^{1}$ Texas has the largest rural population at about 3.8 million rural residents and North Carolina has about 3.2 million rural residents. See:

https://www.census.gov/newsroom/releases/archives/2010 census/cb12-50.html.
}

(Berends, 2015), with many studies raising a number of cautions about charter schools and the implications for public education. First, although some work has suggested that charter schools educationally outperform traditional public schools (e.g. Betts \& Tang, 2011), most researchers agree that evidence is clearly mixed regarding the extent to which charter schools provide consistently superior educational alternatives (e.g. CREDO, 2011; DeJarnatt, 2013; Molnar, 2015; Toma \& Zimmer, 2012). In general, researchers conclude that student achievement in charter schools is no better or worse than student achievement in traditional public schools. However, considerable variation in student outcomes exists by type of charter schools. For example, some of the "no excuses" brick and mortar charter schools such as KIPP have been found to outperform local schools (Nichols-Barrer et al., 2015). Researchers continue to debate the nature of these outcomes, particularly around issues of cream-skimming of students and differential attrition of students from such schools (Angrist, Pathak, \& Walters, 2011; Bifulco \& Ladd, 2006; Fuller, 2013; Hill, Angel, \& Christensen, 2006). Research has found that cyber schools typically substantially under-perform relative to both traditional public schools as well as their brick and mortar charter school counterparts (CREDO, 2015; Research for Action, 2013). Specific to Pennsylvania, CREDO researchers (2015) found that cyber school students exhibited standard deviation learning gains of -0.14 in reading and -0.23 in math for students compared to the "virtual twins" of cyber charter students enrolled in other schools. Translated into days of learning, the effects of enrolling in a Pennsylvania cyber charter school are roughly 90 fewer days of learning in reading and nearly 180 fewer days of learning in mathematics (CREDO, 2015).

Second, while charter schools create new educational options, they may also - depending on the funding formula created by state or local policyundermine public school options that already exist. In Pennsylvania, when a student leaves a traditional public school for a charter school, the revenue for the student that is derived from local and state taxes is paid by the traditional public school district to the charter school. The revenue transferred to the charter school, however, does not reflect the fiscal costs to educate the particular child, but rather the average per pupil cost for educating a child in the sending district. Further, with respect to special education students, charter schools in Pennsylvania on average spend less than one-half of the money they receive for special education students on the education of these students (Hartman, 2015). While the public school no longer provides instruction to the student who has left for a charter school, most district-level fixed costs such as 
utilities and building maintenance remain, with few or no options for districts to make up for funding cuts (e.g., staff reductions) (PSBA, 2014). The result, depending on student enrollment change, can be significant fiscal distress for traditional public school districts, particularly those with smaller economies of scale such as districts located in small towns and rural areas (Bryant, 2010; Gallo, 2014; Hartman, 2015; Schafft et al., 2014). While some argue that the competition from charter schools will force traditional public school districts to reallocate resources in ways that further boost student outcomes (U.S. Department of Education, 2004), research shows that charters do not necessarily have this effect on public school districts (Arsen \& Ni, 2012).

Finally, other observers have raised questions regarding educational equity and the ways in which the charter school system may in fact exacerbate existing patterns of school segregation along racial, linguistic, and class lines that result in unequal access to educational opportunities (Frankenberg, SiegelHawley, \& Wang, 2011; Renzulli \& Evans, 2005). By law, all K-12 students in Pennsylvania are entitled to attend a traditional public school in the school district in which they are located, or any charter they wish to attend with an additional provision that student transportation costs to charter schools are paid by the student's school district for transport within a 10-mile distance of the school district boundary in which the student resides. This means that, in practice, the choice of attending a brick and mortar charter school is often logistically limited by geography - the distance between a student's district and the charter school itself. However, given adequate Internet connectivity (which is typically paid for by cyber charter schools through reimbursements to families), there are no geographic limits for attending cyber charter schools. This means students may opt to enroll in any cyber charter school approved by the state, effectively eliminating the geographic constraint associated with attending brick and mortar schools, whether charter or a traditional public school. In Pennsylvania, this has translated into major enrollment increases in cyber charter schools, and currently Pennsylvania cyber charter schools enroll more than 30,000 students per year, or more than $2 \%$ of the state's total public school enrollment (Schafft et al., 2014; Watson et al., 2014).

Given that brick and mortar charter schooling has tended to proliferate in urban and metropolitan areas rather than rural areas which tend to lack the density of population, capital, and facilities to support charter school creation (Berends, 2015; Bryant, 2010; however, see Smarick, 2014), most research has focused on charters located in urban areas and, to a lesser extent, suburban areas. Indeed, far less is known about how charter schooling may provide differential opportunities and outcomes across urban, suburban, and rural places.

\section{Research Objectives}

To address the lack of research on charter school enrollments across urban, suburban, and rural spaces, this study examines charter school enrollment patterns across geographic locales in Pennsylvania. We examine these patterns using descriptive and inferential statistical methods to examine four years of individual student-level data. The purpose for these analyses is to determine if there is a difference between brick and mortar and cyber charter school enrollment for students from diverse geographic locales. Specifically we investigate whether there are differences in the likelihood that students from diverse geographic locales enroll in brick and mortar charter schools versus cyber charter schools. The remainder of the paper discusses the data, methodology, and findings. The paper concludes by discussing the implications of charter school enrollment patterns for educational equity and what this might mean for students' educational experiences, quality, and access across rural and urban places.

\section{Data}

This study relied on two sources of data. The primary data source was individual student enrollment data for the 2008-09 through 2011-12 academic years provided by the Pennsylvania Department of Education. There were more than 1.5 million student records for each of the four years. The data included a unique identifier for each student, each student's race/ethnicity, each student's individualized education plan (IEP) status, and the school(s) in which each student was enrolled (including multiple enrollment records for students who moved to several schools within a given school year). These data were used to identify whether a given student had enrolled in a traditional public school, brick and mortar charter school, cyber charter school, or multiple types of schools.

We also incorporated data from the National Center for Education Statistics (NCES) to identify the geographic locale of each school district in the state. According to NCES, the locale codes are based on a school's "proximity to an urbanized area" defined as, "a densely settled core with densely settled surrounding areas"

(https://nces.ed.gov/ccd/rural_locales.asp). School districts were identified as being located in one of four locale codes: urban, suburban, town, or rural. While each of the four codes has three subcategories, our analyses relied on the four major 
categories in this study. ${ }^{2}$ Finally, the study incorporated NCES district-level data as a means of determining the percentage of the student's original school district participation rate in the federal free- or reduced-price lunch program as a proxy for economic disadvantage. This combined set of data for each of the four years was then merged together using the unique student identifier. This final dataset allowed us to follow students into and out of various schools during the four-year time frame.

During the merging and data cleaning process, we eliminated a small percentage (less than $0.5 \%$ ) of cases in which a student's school district did not have a geographic locale provided by NCES. Additional student cases were also eliminated for the following reasons: a small number of students for whom a racial/ethnic identifier or IEP status was missing; all students enrolled only in a cyber charter school in the base year (2008-09) since cyber schools do not have an identifiable locale; and, students changing schools multiple times during the base academic year for which there was not a consistent locale. Despite these eliminations, we retained $97 \%$ of the students from the original file.

Since the study considered mobility across all four years, student cases were eliminated for all students who were not enrolled in a school (traditional, brick and mortar charter, or cyber school) for all four years. Possible reasons for the lack of consistent enrollment included: student graduation; student transfer to a school in another state; student transfer to a private school within Pennsylvania; and, student enrollment in a home school option within Pennsylvania. These data exclusions eliminated a further $30 \%$ of the remaining students, with the greatest proportion of exclusions stemming from graduation. Due to our removal of the students not tracked by the Pennsylvania data system and the greater likelihood of cyber school students disappearing from the state data system prior to graduation, our analysis likely underestimates transfers to cyber charter schools (CREDO, 2015). For example, our analysis would not capture a student that transfers from a traditional public school district to a cyber school and then disappears from the state data system prior to graduation.

\section{Methods}

The techniques employed were both descriptive and inferential statistics with two dependent variables as the focus. The first dependent variable was whether a student was ever enrolled in a brick and mortar charter school during the four-year time frame while the second dependent variable was whether a student was ever enrolled in a cyber charter school during the four-year time frame. This study, thus, not only considers the likelihood of a student being in a particular type of school at a given point in time, but also considers the likelihood of a student ever enrolling in a given type of school. Each of the dependent variables were coded as " 1 " if the student was ever enrolled in the given type of charter school and " 0 " if the student was never enrolled in the specific type of charter school.

To examine whether a student from a particular locale enrolled in a brick and mortar charter school or cyber charter school, we simply calculated the percentage of students from each of the four locales that were ever enrolled in a brick and mortar charter school or a cyber charter school. Again, the study used the locale of the school district enrolling the student in the base academic year.

Because the dependent variables were binary, we employed logistic regression analysis in order to provide an estimate of the odds ratio of a student ever enrolling in one of the two types of charter schools. The control variables included the race/ethnicity of a student, a student's IEP status, and the percentage of economically disadvantaged students of the student's school district in the base year. We included the race/ethnicity of the student because a substantial body of research has shown a student's racial/ethnic status influences the odds of the student enrolling in a charter school (Fuller, 2013; Hastings, Kane, \& Staiger, 2005; Hoxby \& Murarka, 2009; Weiher \& Tedin, 2002). We included the IEP status of a student because research has shown special education students are less likely than other students to enroll in charter schools (Fuller, 2013; Howe \& Welner, 2002). Unfortunately, our data did not include information on an individual student's participation in the federal free-/reduced-price lunch program. As a proxy for the individual student's economic status, we included the percentage of economically disadvantaged students enrolled in the student's base school district because research consistently shows that the economic status of a student influences the odds that such a student will enroll in a charter school (Fuller, 2013; Hastings, Kane, \& Staiger, 2005; Hoxby \& Murarka, 2009; Weiher \& Tedin, 2002). Finally, as mentioned, the analytical model included the geographic locale of the school district enrolling the student in order to assess the relationship between geographic locale and enrollment in either a brick and mortar charter school or a cyber charter school.

\footnotetext{
${ }^{2}$ See Appendix A for a description of the geographic locales as defined by NCES.
} 


\section{Findings}

\section{Growth of Charter Schools}

Enrollment in Pennsylvania charter schools overall increased 44 percent between the 2008-09 and 2011-12 academic years. Specifically, as shown in Figure 1, while just over 73,000 students in Pennsylvania were enrolled in charter schools in the 2008-09 academic year, by 2011-12 that number had increased to nearly 105,000 . The greatest enrollment increases during this time period were accounted for by urban brick and mortar charter schools (representing a $48 \%$ increase in enrollment) and cyber schools (representing a $44 \%$ increase in enrollment). Strikingly, the increase in the number of students enrolled in urban brick and mortar charter schools exceeded the total number of new charter school students enrolled in all other charter schools, including cyber schools. Concomitantly, cyber charter enrollments accounted for more than $30 \%$ of all state charter school students by 2011-12. Rural brick and mortar charter schools had the lowest enrollment increase at $25 \%$. In the case of brick and mortar charter schools in both rural and town areas, the overall percentage increase in enrollment must be understood within the context of low enrollment overall. For example, brick and mortar charter enrollments in towns increased from 767 to 1,082 and from 1,851 to 2,308 in rural areas (see Figure 1).

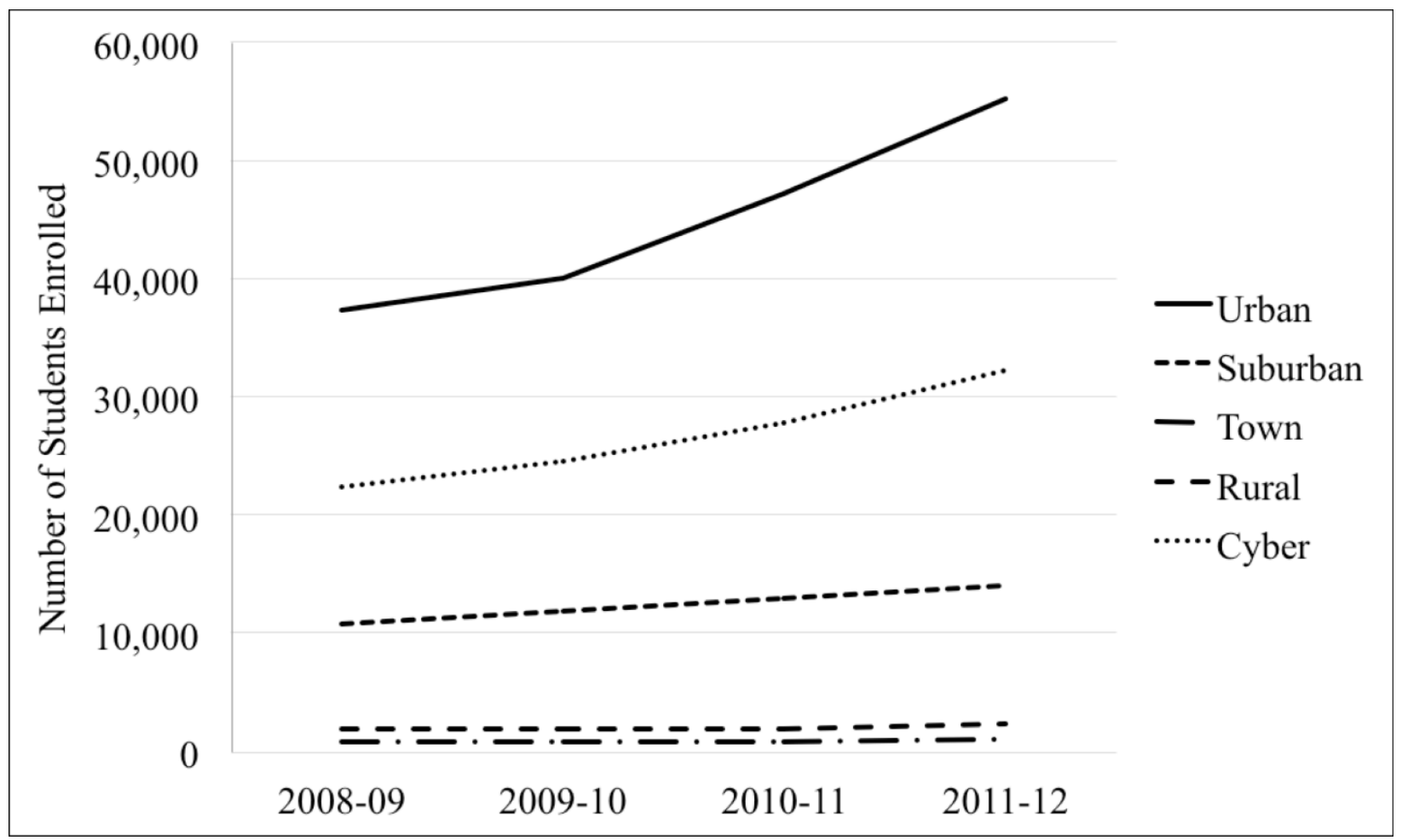

Figure 1

Charter School Enrollment Change by Location, 2008-2009 to 2011-2012. Data accessed from the Pennsylvania Department of Education; U.S. Department of Education, National Center for Education Statistics, Common Core of Data (CCD).

As is the case in many other states, the total number of urban brick and mortar charter schools was greater than in any other locale (see Table 1). In addition, the increase in urban brick and mortar schools between 2008-09 and 2011-12 was three times the increase in all other brick and mortar charter schools combined. While the overall number of cyber charters increased from 11 to 12 during the time period, this negligible increase in the number of cyber charters belies the cyber charter enrollment increases overall- that is, an increase in the cyber charter enrollment of nearly 10,000 students (see Figure 1). By contrast, the number of brick and mortar charter schools in rural and town areas combined during this period increased from 11 to 15-a 36\% increase - but only evidenced a total enrollment increase of less than 800 students. 
Table 1

Number and Percent Change in Charter Schools by Geographic Location, 2008-09 to 2011-12

\begin{tabular}{lllllll}
\hline \multirow{2}{*}{$\begin{array}{l}\text { Geographic } \\
\text { Location }\end{array}$} & \multicolumn{3}{c}{ Academic Year } & \multicolumn{2}{c}{ 4 Year Change } \\
\cline { 2 - 6 } Charter Schools & $2008-09$ & $2009-10$ & $2010-11$ & $2011-12$ & $\mathrm{~N}$ & $\%$ \\
\hline Urban & 80 & 86 & 94 & 105 & 25 & $31 \%$ \\
Suburban & 25 & 26 & 27 & 29 & 4 & $16 \%$ \\
Town & 3 & 3 & 4 & 5 & 2 & $67 \%$ \\
Rural & 8 & 8 & 8 & 10 & 2 & $25 \%$ \\
Cyber & 11 & 11 & 11 & 12 & 1 & $9 \%$ \\
All Schools & 127 & 134 & 144 & 161 & 34 & $27 \%$ \\
\hline
\end{tabular}

Note: Data accessed from the Pennsylvania Department of Education; U.S. Department of Education, National Center for Education Statistics, Common Core of Data (CCD).

The data further indicate that more than $18 \%$ of urban students have enrolled in a brick and mortar charter school at least once (see Figure 2), compared to fewer than $3 \%$ of suburban students, and fewer than $1 \%$ of town and rural students. Across geographic locales, however, a relatively even proportion of students enrolled in cyber schools. Specifically, a little more than $3 \%$ of students in rural and urban areas ever enrolled in cyber charter schools, while town and suburban students enrolled just below 3\% and just above $2 \%$ respectively. These indicators suggest that in Pennsylvania brick and mortar charter schools are disproportionately an urban phenomenon while cyber charter schools have more or less an even proportional distribution across geographic locales.

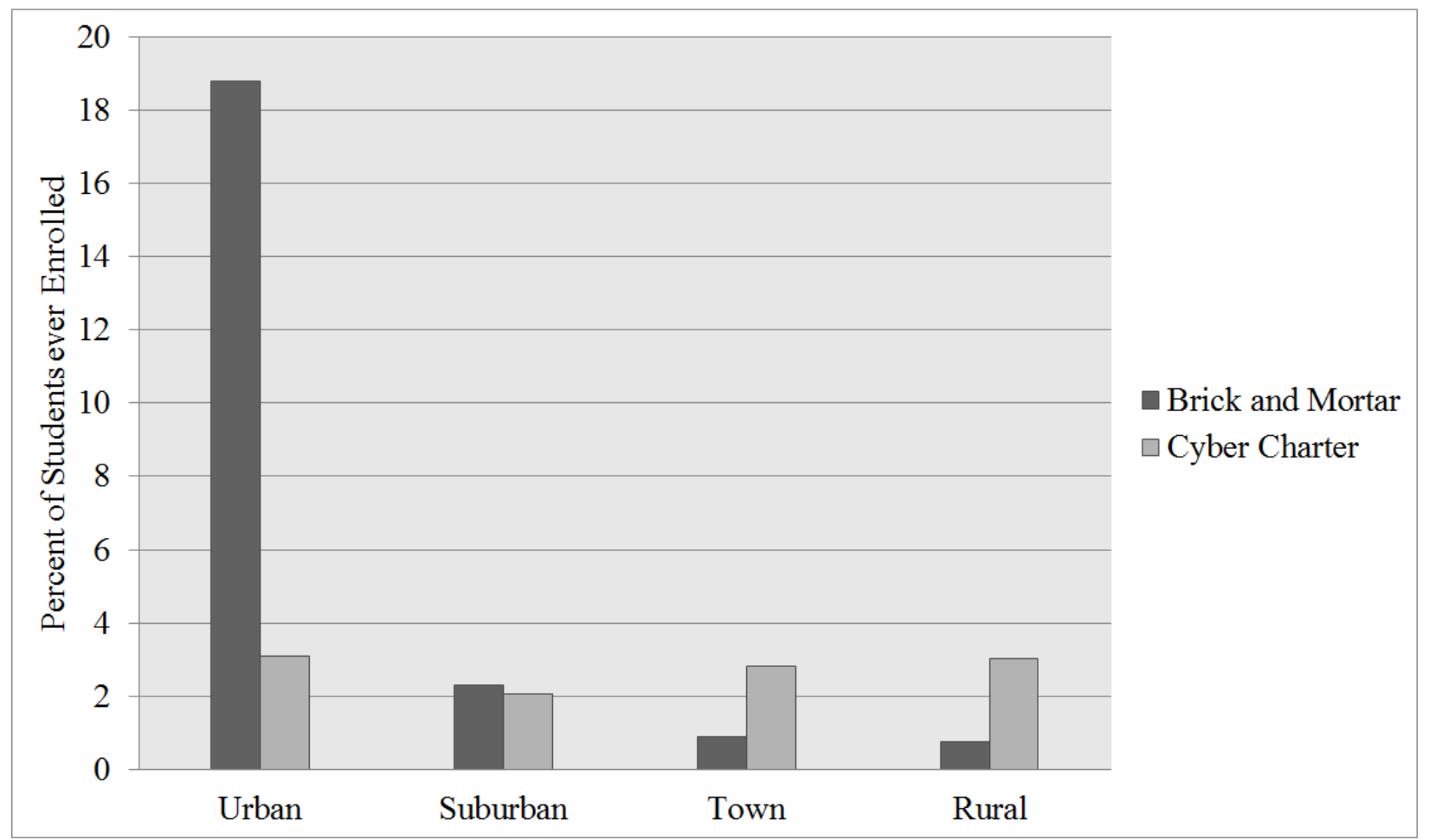

Figure 2

Percent of Students in each Locale ever Enrolled in Charter Schools, 2008-09 to 2011-12. Data accessed from the Pennsylvania Department of Education; U.S. Department of Education, National Center for Education Statistics, Common Core of Data (CCD). 


\section{Likelihood of Enrolling in Brick and Mortar and Cyber Charter by Locale}

In our logistic regression analysis, we chose rural school districts as our comparison group. Thus, the logistic regression results for students enrolled in schools in urban, suburban, and town locales is interpreted as being in reference to students enrolled in schools located in rural areas of the state. The analysis estimates the odds of a student enrolling in a specific type of charter school after controlling for student factors that research has shown are associated with the odds of a student enrolling in a charter school (race/ethnicity, IEP status, and percentage of economically disadvantaged students in the school enrolling the student).

Brick and Mortar Charter Schools. As shown in Table 2, both students from urban and suburban areas were far more likely to enroll in a brick and mortar charter school than students from rural areas. Specifically, students from urban areas were about 5.9 times more likely than students from rural areas to enroll in a brick and mortar charter school while students from suburban areas were about 2.7 times more likely than students from rural areas to enroll in a brick and mortar charter school. There was not a statistically significant difference in the likelihood of students from town and rural areas enrolling in a brick and mortar charter school. In addition to these central findings on locale, the model suggests that other student and school district characteristics are related to enrollment in brick and mortar charter schools. With the exception of multiracial students, all other students of color were more likely than White students to enroll in a brick and mortar charter. Notably, students with an IEP were, on average, slightly less likely to enroll in a brick and mortar charter school. 
Table 2

Odds Ratio that a Student Enrolls in the Two Types of Charter School, 2008-09 to 2011-12

Odds Ratio of Ever

Enrolled in

Brick and Mortar
Odds Ratio of Ever Enrolled in Cyber Charter

\section{Geographic Locale \\ (Reference: Rural)}

\begin{tabular}{|c|c|c|}
\hline Urban & $\begin{array}{l}5.871 * * \\
(.160)\end{array}$ & $\begin{array}{l}.537 * * \\
(.012)\end{array}$ \\
\hline Suburban & $\begin{array}{l}2.710 * * \\
(.069)\end{array}$ & $\begin{array}{l}.794 * * \\
(.012)\end{array}$ \\
\hline Town & $\begin{array}{l}1.067 \\
(.038) \\
\end{array}$ & $\begin{array}{l}.863 * * \\
(.017) \\
\end{array}$ \\
\hline Special Education & $\begin{array}{l}.942 * * \\
(.011)\end{array}$ & $\begin{array}{l}1.265^{* *} \\
(.019)\end{array}$ \\
\hline Economic Disadvantage & $\begin{array}{l}1.239 * * \\
(.004)\end{array}$ & $\begin{array}{l}1.231 * * \\
(.005)\end{array}$ \\
\hline $\begin{array}{l}\text { Race } \\
\text { (Reference: White) }\end{array}$ & & \\
\hline American Indian & $\begin{array}{l}1.377^{*} \\
(.177)\end{array}$ & $\begin{array}{l}1.968 * * \\
(.204)\end{array}$ \\
\hline Asian & $\begin{array}{l}1.319 * * \\
(.036)\end{array}$ & $\begin{array}{l}.294 * * \\
(.018)\end{array}$ \\
\hline Black & $\begin{array}{l}3.404 * * \\
(.044)\end{array}$ & $\begin{array}{l}.764 * * \\
(.014)\end{array}$ \\
\hline Latina/o & $\begin{array}{l}1.761 * * \\
(.027)\end{array}$ & $\begin{array}{l}.616 * * \\
(.016)\end{array}$ \\
\hline Multiracial & $\begin{array}{l}.726 * * \\
(.044)\end{array}$ & $\begin{array}{l}.343 * * \\
(.038)\end{array}$ \\
\hline Constant & $\begin{array}{l}.004 * * \\
(.000)\end{array}$ & $\begin{array}{l}.016 * * \\
(.000)\end{array}$ \\
\hline Pseudo $\mathbf{R}^{2}$ & .24 & .02 \\
\hline
\end{tabular}

Notes: Standard error in parentheses. Economic disadvantage can be interpreted as in increase in 10 percentage points of free and reduced lunch of school district equals represented odds ratio increase. Data accessed from the Pennsylvania Department of Education; U.S. Department of Education, National Center for Education Statistics, Common Core of Data (CCD). ${ }^{* *} \mathrm{p}<.01 .{ }^{*} \mathrm{p}<.05$

Cyber Charter Schools. Compared to students from rural areas, students from the other three locales were statistically significantly less likely to enroll in a cyber charter school. Specifically, students from urban areas were approximately $46 \%$ less likely to enroll in a cyber charter school than students from rural areas (calculated by subtracting the odds ratio 0.537 from 1.000), while students from suburban areas were about $21 \%$ less likely to enroll in a cyber charter school than students from rural areas (Table 2 ). On average, students from town areas were about $14 \%$ less likely to enroll in a cyber charter school than students from rural areas. With the exception of
American Indian students, students of color were less likely to enroll in cyber charter schools - even after controlling for locale. In addition, students with an IEP were about $27 \%$ more likely to ever enroll in a cyber charter.

Additionally, only $54.8 \%$ of the students stay enrolled in cyber schools throughout all four years of the dataset. This is an important sub-finding in that it indicates a high level of cyber charter school enrollment churn. However, the caveat of this finding is that it does not show the direction of the moves (leaving or staying and in what order). It does, however, suggest that cyber charter schools are 
associated with high levels of student mobility and disrupted educational experience.

\section{Discussion}

As Berends (2015) argues, a better understanding of the social and institutional contexts of both charter schools and traditional public schools is needed to effectively determine the conditions under which school choice and charter schools yield a range of positive (or negative) academic outcomes, including student achievement, educational equity, and schools that are able to maintain their status as strong local institutions. Geographic disparities with regard to brick and mortar charter schools reflect how economies of scale tend to foster the creation of brick and mortar charter schools in urban and suburban rather than rural places. It is likely that this geographic disparity will not change in the immediate future, thus leaving cyber charter schools as the primary option of choice for families in rural settings.

This should be a concern for rural school district stakeholders because of the negative educational performance outcomes associated with cyber charter schools. We find that rural students are proportionately more likely to enroll in cyber charter schools than in brick and mortar charter schools when they leave traditional public schools. However, Pennsylvania cyber charter schools substantially underperform compared to traditional public schools. Indeed, in $98 \%$ of instances in which a student in Pennsylvania transferred from a traditional public school to a cyber charter school, the cyber charter had lower percentages of students scoring at proficient or above on state mathematics assessments (Schafft et al., 2014). The same was true for $86 \%$ of student transfers from traditional public schools to cyber charter schools with regard to state reading assessments (Schafft et al., 2014). Thus, with regard to both mathematics and reading, the overwhelming majority of student transfers from traditional public schools to cyber charters represented moves from higher performing to lower performing academic environments. This is a concern for rural students because this suggests that not only are the choice options for rural students more limited than for nonrural students, but that the available options do not provide schools with strong academic outcomes.

That said, the analyses presented here, and in studies of cyber charter schools generally, may reflect some degree of selection bias - that is, students transferring from traditional public schools to cyber charter schools cannot be assumed to be representative of the student population overall. It is possible that students leaving traditional public school districts for charter schools are disproportionately underperforming relative to their peers. However, the 2011 CREDO study (CREDO, 2011) found that the starting test score for students entering cyber charter schools depicted statistically significant greater academic achievement. While this may be true, estimates of student growth that controlled for prior academic achievement and other characteristics of students (mobility, race/ethnicity, age, gender), found that students enrolled in Pennsylvania cyber charter schools substantially underperform both their traditional public school peers and their peers enrolled in brick and mortar charter schools (CREDO, 2011). These findings were buttressed by CREDO (2015) which analyzed cyber charter schools nationwide and found similar results, this time matching the students in cyber charter schools to "statistical twins" in traditional schools and still finding inadequate academic growth. These researchers argued that the outcome was statistically equivalent to not going to school at all. While the CREDO analyses do not make a direct comparison between students specifically in rural settings, the significant differences in learning outcomes between cyber charter school students and traditional public school students strongly suggest that students transferring from a traditional rural public school to a cyber charter school would have likely been better off academically had the students remained in the rural school.

There are additional concerns for equity based on the finding that cyber charter students are more likely to be identified as special education students and more likely to be from schools with high levels of free and reduced-price lunch program participation. It intuitively seems that students from disadvantaged backgrounds and special education status need more in-person services and professional support. For example, free and reduced-price lunch students are entitled to receive lunch and other food supplements from their schools and IEP students are entitled to a range of other services that often require face-to-face interactions. It is unclear the extent to which cyber students are receiving such services. Clearly these students are opting out of the traditional public school, thus indicating a lack of satisfaction in the traditional option provided to them. Some research suggests that students leave for virtual schools because of feelings of improved safety and more suitable teaching options for their personal conditions (Beck, Egalite, \& Maranto, 2014). What is clear is that, in the Pennsylvania context, transferring from a rural school district to a cyber charter school is unlikely to result in an academic advantage for the child. However, the reasons for this dissatisfaction are not clear and should be explored further. Future research should more closely examine who leaves, why, and whether leaving students receive adequate 
and equitable services through their new educational choice.

Additionally, there are equity concerns for the students in the low-income districts that are not choosing cyber charter schools but are seeing their fellow students leave. As mentioned, funding follows the students leaving the traditional school and entering a charter school. Therefore, resources that low-income districts depend upon are depleted with every student that leaves for a cyber charter school. Evidence suggests this depletion of funds has a deleterious effect on the ability of rural schools to offer a high-quality education (Kotok, Kryst, \& Hagedorn, 2015; Schafft, et al., 2014) although more research is clearly needed to further explore these fiscal implications.

Another concern is the way in which charter schools are associated with high levels of student mobility across educational institutions. A large body of scholarship has documented the negative achievement outcomes for students who have disrupted educational experiences because of school transfers (see Killeen \& Schafft, 2015; Rumberger \& Thomas, 2000; among others). This is a particular cause for concern given the underperformance of cyber charter schools - the charter school type most accessible for rural students. The percentage of students maintaining continuous enrollment in charter school districts, particularly cyber charter schools, for even three or four years was considerably lower than their peers enrolled in traditional public school districts. In our data, only $54.8 \%$ of the students stayed enrolled in cyber schools throughout all four years of the dataset. While not the focus of our study, it is nonetheless an area in need of future research, as the educational disruption associated with high levels of inter-school mobility could adversely affect students transferring back and forth between cyber schools, brick and mortar charter schools, and traditional public schools.

A last concern is the disproportionate social, civic and economic role that public schools play in rural communities. Rural schools are often the largest employer in the areas they serve, they help strengthen community identity, and their presence is associated with a number of social and economic benefits including lowered poverty rates, increased real estate values and higher levels of local entrepreneurship (Lyson, 2002; Schafft, 2016; Tieken, 2014). It is unclear whether rural schools will provide the same level of local assets to a community if resources and funding are diverted to charter schools and in particular, cyber charter schools that do not have a geographic footprint in rural areas. The result is a weakening of the role of local rural schools in their ability to provide the "social glue" that helps to hold communities together, foster community commitment to local education, and enhance civic community.

This is not to say that there are not circumstances in which online learning or online courses in general could provide a benefit to rural students. For example, Advanced Placement (AP) courses or foreign language courses could expand the offerings of small rural school districts if they do not have the capacity to offer these courses. However, the current model where students leave for cyber charters at a steep financial cost to public schools is not the only way to make these options available for this population of students. Another conceivable model is to have the options for these course enrollments offered at the Intermediate Unit (an intermediary organization between the school district and state department of education) or state level, providing similar access to online courses that the students desire without penalizing the districts for their inability to serve this selected population of students through their lack of capacity to offer online courses.

In general, our analysis and discussion suggest that, in the case of charter schools, the application of federal and state policy to rural areas may not translate well due to the nature of rural communities and their relationship to public school districts. The charter school options for rural students are likely to largely remain cyber options, yet these options may offer inferior educational services. Further, while the likelihood of exposure to inadequately performing choice programs is heightened for rural students with the growth of cyber charter enrollment, the funding for these programs has largely rested on the finances of the traditional public schools. This funding situation has the potential to not only negatively affect the students that leave for cyber charter schools, but also those who choose to stay. If cyber charter schools are truly the negative academic programs that are been reflected in performance metrics, rural educators, leaders, and policymakers should understand these negative influences and develop strategies to mitigate them.

Increased oversight for cyber charter schools, including investigating the causes of high mobility rates, is needed to ensure that cyber charters represent a meaningful, high quality choice for rural students. The disproportionate likelihood of rural public school districts being affected by transfers of students to cyber charter schools rather than brick and mortar schools also suggests the need to revisit current state policy that requires public school districts to send the entire per-pupil expenditure for each district student who enrolls in cyber charter schools. If educational reformers are serious about maintaining strong local educational institutions that provide quality educational experiences and enhance community 
civic capacity, they ought to exercise caution with regard to charter schools so that the charter school option, especially in rural areas, does not further weaken existing educational institutions and infrastructure while simultaneously providing educational options that may be inferior to what already exists.

\section{Appendix A - Definitions of Locale Used in the Study}

\section{Urban}

- $\quad$ City, Large: Territory inside an urbanized area and inside a principal city with population of 250,000 or more.

- $\quad$ City, Midsize: Territory inside an urbanized area and inside a principal city with population less than 250,000 and greater than or equal to 100,000 .

- $\quad$ City, Small: Territory inside an urbanized area and inside a principal city with population less than 100,000.

\section{Suburban}

- Suburb, Large: Territory outside a principal city and inside an urbanized area with population of 250,000 or more.

- $\quad$ Suburb, Midsize: Territory outside a principal city and inside an urbanized area with population less than 250,000 and greater than or equal to 100,000 .
- Suburb, Small: Territory outside a principal city and inside an urbanized area with population less than 100,000 .

\section{Town}

- Town, Fringe: Territory inside an urban cluster that is less than or equal to 10 miles from an urbanized area.

- Town, Distant: Territory inside an urban cluster that is more than 10 miles and less than or equal to 35 miles from an urbanized area.

- Town, Remote: Territory inside an urban cluster that is more than 35 miles from an urbanized area.

\section{Rural}

- Rural, Fringe: Census-defined rural territory that is less than or equal to 5 miles from an urbanized area, as well as rural territory that is less than or equal to 2.5 miles from an urban cluster.

- Rural, Distant: Census-defined rural territory that is more than 5 miles but less than or equal to 25 miles from an urbanized area, as well as rural territory that is more than 2.5 miles but less than or equal to 10 miles from an urban cluster.

- Rural, Remote: Census-defined rural territory that is more than 25 miles from an urbanized area and is also more than 10 miles from an urban cluster.

\section{References}

Angrist, J. D., Pathak, P. A., \& Walters, C. R. (2011, Aug). Explaining charter school effectiveness (No. w17332). Washington, DC: National Bureau of Economic Research.

Arsen, D., \& Ni, Y. (2012). The effects of charter school competition on school district resource allocation. Educational Administration Quarterly, 48(1), 3-38.

Bankston, C.L., Ravitch, D., Petrilli, L.A., Paino, M., \& Bonastia, C. (2013). Charter schools. Contexts, 12, 16-25.

Beck, D., Egalite, A., \& Maranto, R. (2014). Why they choose and how it goes: Comparing special education and general education cyber student perceptions. Computers \& Education, 76, 7079.

Berends, M. (2015). Sociology and school choice: What we know after two decades of charter schools. Annual Review of Sociology, 41, 15980.

Betts, J.R., \& Tang, Y.E. (2011). The effect of charter schools on student achievement: A metaanalysis of the literature. Seattle, WA: Center on Reinventing Public Education.

Bifulco, R., \& Ladd, H. F. (2006). The impacts of charter schools on student achievement: Evidence from North Carolina. Education Finance and Policy, 1(1), 50-90.

Bryant, J. (2010). Dismantling rural stereotypes. Educational Leadership, 68(3), 54-58.

Center for Research on Educational Outcomes (CREDO). (2011). Charter school performance in Pennsylvania. Stanford, CA: CREDO.

Center for Research on Educational Outcomes (CREDO). (2015). Online charter school study. Stanford, CA: CREDO. 
DeJarnatt, S.L. (2013). Keep following the money: Financial accountability and governance of cyber charter schools. The Urban Lawyer, 45(4), 915-951.

Frankenberg, E., Siegel-Hawley, G., \& Wang, J. (2011). Choice without equity: Charter school segregation. Education Policy Analysis Archives, 19(1).

Fuller, E. J. (2013). Cream skimming in Texas: A comparison of the characteristics of students entering high-profile charter schools in the same zip code. Texas Education Review, 1(2), $25-42$.

Gallo, P.J. (2014). Reforming the "business" of charter schools in Pennsylvania. Brigham Young University Education and Law Journal, 2, 207-232.

Gronberg, T., Jansen, D., \& Taylor, L. (2012). The relative efficiency of charter schools: A cost frontier approach. Economics of Education Review, 31(2), 302-317.

Hartman, W.T. (2015). Analysis of special education enrollments and funding in Pennsylvania rural and urban districts. Harrisburg, PA: The Center for Rural Pennsylvania.

Hastings, J. S., Kane, T. J., \& Staiger, D. O. (2005). Parental preferences and school competition: Evidence from a public school choice program (No. w11805). National Bureau of Economic Research.

Henig, J.R. (2012). Charter inroads in affluent communities: Hype or turning point? In R.J. Lake (Ed.), Hopes, fears, \& realities: A balanced look at American charter schools in 2012 (pp. 1-20). Bothel, WA: University of Washington, Center on Reinventing Public Education.

Hill, P. T., Angel, L., \& Christensen, J. (2006). Charter school achievement studies. Education Finance and Policy 1(1), 139-150.

Howe, K. R., \& Welner, K. G. (2002). School choice and the pressure to perform: Déjà vu for children with disabilities? Remedial and Special Education, 23(4), 212-222.

Howley, C. (2014). Review of a new frontier: Utilizing charter schooling to strengthen rural education. Boulder, CO: National Education Policy Center.

Hoxby, C. M., \& Murarka, S. (2009). Charter schools in New York City: Who enrolls and how they affect their students' achievement. NBER Working Paper No. 14852. National Bureau of Economic Research.

Johnson, J., Showalter, D., Klein, R., \& Lester, C. (2014). Why rural matters 2013-14: The condition of rural education in the 50 States.
Washington, DC: Rural School and Community Trust.

Killeen, K., \& Schafft, K. A. (2015). The organizational and fiscal implications of transient student populations in urban and rural areas. In H. F. Ladd \& E .B. Fiske (Eds.), Handbook of research in education finance and policy, revised second ed. (pp. 623-63). New York: Routledge.

Kotok, S., Kryst, E., \& Hagedorn, A. (2015). Challenges for rural school leaders in the $21^{\text {st }}$ century: A case study of Brockway, Pennsylvania. In S.M Williams \& A.A. Grooms (Eds.), The politics of educational opportunity in rural contexts. Charlotte: Information Age Publishing.

Lyson, T.A. (2002). What does a school mean to a community? Journal of Research in Rural Education, 17(3), 131-137.

Molnar, A., Huerta, L., Shafer, S. R., Barbour, M. K., Miron, G., \& Gulosino. (2015). Virtual schools in the U.S. 2015: Politics, performance, policy, and research evidence. Boulder, CO: National Education Policy Center.

Nichols-Barrer, I., Gleason, P., Gill, B., \& Tuttle, C.C. (2015). Student selection, attrition, and replacement in KIPP middle schools.

Educational Evaluation and Policy Analysis, 38(1), 5-20.

Pennsylvania School Board Association (PSBA). (2014). The costs of charter and cyber charter schools. Mechanicsburg, PA: Pennsylvania School Board Association.

Peters, M.A. (2012). Neoliberalism, education and the crisis of Western capitalism. Policy Futures in Education, 10(2), 134-141.

Renzuli, L.A., \& Evans, L. (2005). School choice, charter schools, and white flight. Social Problems, 52(3), 398-418.

Research for Action (2013). Issue brief: An analysis of Pennsylvania's cyber charter schools. Accessed at http://www.researchforaction.org/wpcontent/uploads/2013/12/RFA-Issue-Brief-onCyber-Charters-Nov-2013.pdf

Rumberger, R. W., \& Thomas, S. L. (2000). The distribution of dropout and turnover rates among urban and suburban high schools. Sociology of Education, 73(1), 39-67.

Schafft, K., Frankenberg, E., Fuller, E., Harman, W., Kotok, S., \& Mann, B. (2014). Assessing the enrollment trends and financial impacts of charter schools on rural and non-rural school districts in Pennsylvania. Harrisburg, PA: The Center for Rural Pennsylvania. 
Schafft, K.A. (2016) Rural education as rural development: Understanding the rural schoolcommunity well-being linkage in a $21^{\text {st }}$ century policy context. Peabody Journal of Education, 91(2), 137-154.

Siegel-Hawley, G., \& Frankenberg, E. (2011). Does law influence charter school diversity? An analysis of federal and state legislation. Michigan Journal of Race \& Law, 16(2): 321376.

Smarick, A. (2014). A new frontier: Utilizing charter schooling to strengthen rural education. Boston, MA: Bellwether Education Partners.

Tieken, M.C. (2014). Why rural schools matter. Chapel Hill: University of North Carolina Press.
Toma, E., \& Zimmer, R. (2012). Two decades of charter schools: Expectations, reality and the future. Economics of Education Review, 31(2), 209-12.

U.S. Department of Education. (2004). Successful charter schools. Washington D.C.: U.S. Department of Education.

Watson, J., Pape, L., Murin, A., Gemin, B. \& Vashaw, L. (2014). Keeping pace with K-12 digital learning: An annual review of policy and practice, eleventh ed. Mountain View, CA: Evergreen Education Group.

Weiher, G. R., \& Tedin, K. L. (2002). Does choice lead to racially distinctive schools? Charter schools and household preferences. Journal of Policy Analysis and Management, 21(1), 79-92.

\section{About the authors:}

Bryan Mann is a Ph.D. candidate in the Educational Theory and Policy program at Penn State University. His research interests include educational policy \& leadership, charter schools, K-12 online education, and GIS and quantitative methods.

Stephen Kotok is an Assistant Professor of Educational Leadership and Foundations at the University of Texas at El Paso. His research interests include educational policy, charter schools, school climate, the effects of social stratification on $\mathrm{K}-12$ education, and quantitative methods.

Erica Frankenberg is an Associate Professor of Education and Demography in the Department of Education Policy Studies at Penn State University. Her research interests focus on racial desegregation and inequality in $\mathrm{K}-12$ schools, school choice and racial stratification, and the connections between school segregation and other metropolitan policies.

Ed Fuller is an Associate Professor in the Department of Education Policy Studies at Penn State University. His research interests include school and district leaders, evaluation, and charter school issues.

Kai A. Schafft is an Associate Professor in the Department of Education Policy Studies at Penn State University. He conducts research on rural education and the relationship between spatial and social inequality. 